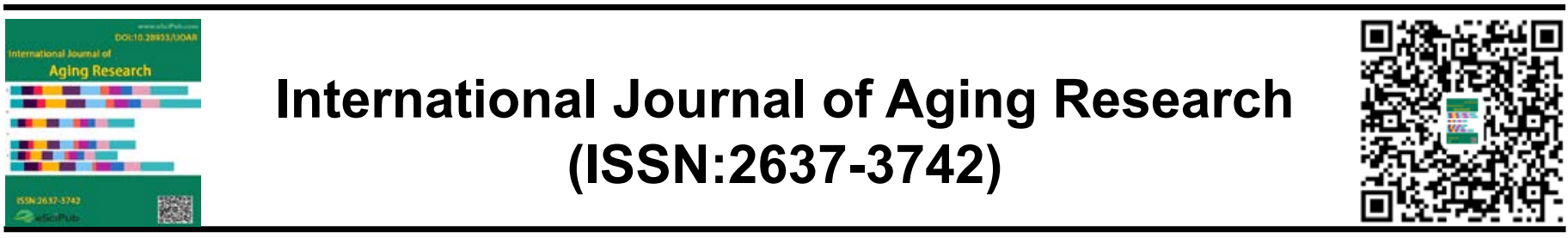

\title{
Risks factors for significant injury after geriatric falls
}

\author{
Jon D. Dorfman MD ${ }^{1}$, Allison Wyman $\mathbf{M S}^{2}$, Gordon FitzGerald $\mathrm{PhD}^{2}$, Timothy A. Emhoff MD ${ }^{1}$, \\ Fred A. Anderson PhD' ${ }^{2}$, Heena P. Santry MD $\mathrm{MS}^{3}$
}

${ }^{1}$ Department of Surgery, University of Massachusetts Memorial Medical Center Worcester, MA; ${ }^{2}$ University of Massachusetts Medical School, Worcester, MA; 3Department of Surgery, The Ohio State University Wexner Medical Center, Columbus, OH (formerly at 1,2)

\section{ABSTRACT}

Elderly falls are a healthcare epidemic. We aimed to identify risk factors of serious falls by linking data on functional status from the Global Longitudinal Study of Osteoporosis in Women (GLOW) and our institutional trauma registry. 124 of 5,091 local women enrolled in GLOW were evaluated by our trauma team for injuries related to a fall during the study period. Median injury severity score was 9 . The most common injuries were intertrochanteric femur fracture $(n=25,9.8 \%)$ and skin contusion/hematoma to face $(n=12,4.7 \%)$. Injured women were older than the uninjured cohort (median 80 versus 68 years), more likely to have cardiovascular disease and osteoarthritis, and less likely to have high cholesterol. Prospectively collected Short Form 36 (SF-36) baseline activity status revealed greater limitation in all assessed activities in women evaluated for fall-related injuries in our trauma center. In multivariable analysis, age (per 10 year increase) and two or more self-reported falls in the baseline survey were the strongest predictors of falling (both HR 2.4, p $<0.0001$ and $p<0.001$ respectively), followed by history of osteoarthritis (HR $1.6, p=0.01$ ). Functional status was no longer associated with risk of fall when adjusting for these factors.

Functional status appears to be a surrogate marker for frailty. With the aging of the US population and long lifespan of American women, this finding has important implications for both fall prevention strategies and research intended to better understand why aging women fall as burdensome validated metrics may not be the best indicators of fall risk.

The authors have no conflict of interests to declare. Funding statement: This work was partially supported by grants from NIH (8KL2TR000160-03), AHRQ (R01HS22694), and PCORI (ME1310-07682) to HS.

\section{Keywords:}

geriatric, falls, trauma

*Correspondence to Author:

Jon Dorfman, MD

Department of Surgery, Division of Trauma and Surgical Critical Care University Campus, 55 Lake Avenue North Worcester, MA 01655

How to cite this article:

Jon D. Dorfman, Allison Wyman, Gordon FitzGerald, Timothy A. Emhoff, Fred A. Anderson, Heena P. Santry.Risks factors for significant injury after geriatric falls. International Journal of Aging Research, 2019, 2:27

\section{eScîPub}

eSciPub LLC, Houston, TX USA. Website: http://escipub.com/ 


\section{Background}

The United States population is aging and the number of individuals over the age of 65 is expected to nearly double to over 80 million by 2050. (1) With the increase in age, a noticeable increase in geriatric trauma due to falls has occurred. (2) Unlike with younger patients, severe injuries and even death occur from low energy falls in geriatric patients. $(3,4)$

The impact of falls on the geriatric patients and the healthcare system has led to many prevention programs. These include exercise and balance training classes $(5,6,7)$, home inspections, $(8,9)$ and medication initiatives. (10) The identification of individuals at high risk of serious falls could further these efforts. Unfortunately, assessing these risk factors at the time of hospitalization for fall-related injuries is confounded by multiple factors including recall bias and need for querying proxies in cases of injury precluding participation in a risk assessment. There is paucity of prospective data on health and functional status for persons who might later fall.

From January 1, 2006 to January 31, 2013, the Global Longitudinal Study of Osteoporosis (GLOW) surveyed women age 55 and older for a number of health and functional status parameters. We link this pre-injury data collected from the GLOW study to injury data from the Trauma Registry at our regional Level 1 trauma center, to identify risk factors of falling and sustaining serious injury in this cohort. We hypothesized that preinjury baseline GLOW activity status data would correlate with risk of injury requiring trauma surgical evaluation. Specifically, we anticipated that reduced functional status on validated metrics would predict risk of falls.

\section{Methods}

GLOW was an international study of osteoporosis administered by the University of Massachusetts Medical School (Worcester, MA). The study included women over the age of 55 years old (inclusion criteria have been previously published) in 17 locations around the globe (11). The Worcester, MA USA GLOW cohort included 5,091 women from the local community. UMass Memorial Medical Center in Worcester, MA is the only verified American College of Surgeons Level 1 trauma center in central Massachusetts and serves as the regional tertiary referral center. A prospective trauma registry is maintained by the trauma center. (12) The UMass Memorial Trauma Registry was queried for trauma patients who met the GLOW inclusion criteria during the GLOW study period from January 1, 2006 to January 31,2013 (3,326 women over the age of 55). The GLOW and registry data sets were cross referenced by name and date of birth to obtain the list of GLOW participants who were seen for traumatic injury at UMass Memorial from January 1, 2006 until January 31, 2013. We then included only those patients whose mechanism of injury was fall (ICD-9-CM E Codes E880 - 888). This inpatient hospital information was linked with the GLOW survey data and then de-identified.

From the GLOW database baseline survey (conducted from October 1,2006 through March $31,2008)$, we obtained base line age, comorbidities, hospitalizations in the prior year, number of outpatient visits in the prior year, number of falls, and Short Form-36 activity data. Short Form 36 (SF36) activity is a self-reported validated survey of exercise activity and activities of daily living. (13) Response categories include "not limited", "limited a little" or "limited a lot". Due to the sample size, we combined the categorical responses of "limited a little" or "limited a lot"; our activity status categories were therefore women who reported "not limited" versus any limitation of the queried activity. The UMass Memorial trauma registry provided initial admission vital signs, injury patterns and injury severity score.

GLOW patients who were and were not treated for falls at our trauma center (injured by fall study group and uninjured comparison group) were compared using the Mann-Whitney $U$ test for 
continuous variables (shown as medians with $25^{\text {th }}$ and $75^{\text {th }}$ percentiles) and Fisher's exact test or the chi square test for categorical variables (shown as frequency and proportion). A KaplanMeier curve was constructed to examine time between the GLOW baseline survey and fallbased trauma activation. Cox proportional hazards model requiring evaluation and treatment for fall at our trauma center was then fit using backwards selection, beginning with all variables that were significant $(p<0.20)$ on univariate analyses. Variables that were significant $(p<0.05)$ were retained in the final model. All analyses were performed in SAS version 9.3. The University of Massachusetts Medical School Institutional Review Board approved the review and linkage of the Worcester cohort of GLOW and the UMass Memorial Trauma Registry.

\section{Table 1. Comorbidities from the GLOW Baseline Survey.}

\begin{tabular}{|c|c|c|c|c|}
\hline Comorbidities, n(\%) & & $\begin{array}{l}\text { Uninjured } \\
(n=4945)\end{array}$ & $\begin{array}{c}\text { Injured by fall } \\
(n=124)\end{array}$ & $\mathrm{p}$-value \\
\hline & Hypertension & $2758(56)$ & $87(70)$ & 0.002 \\
\hline & High Cholesterol & $2934(60)$ & $61(51)$ & 0.035 \\
\hline & Heart disease & $794(16)$ & $35(28)$ & $<0.001$ \\
\hline & Asthma & $720(15)$ & $18(15)$ & 0.99 \\
\hline & COPD/emphysema & $401(8.2)$ & $19(16)$ & 0.003 \\
\hline & Osteoarthritis/DJD & $1544(32)$ & $59(48)$ & $<0.001$ \\
\hline & Stroke & $204(4.2)$ & $12(9.8)$ & 0.003 \\
\hline & Parkinsons & $14(0.3)$ & $1(0.8)$ & $0.31^{*}$ \\
\hline & Multiple sclerosis & $35(0.7)$ & $0(0.0)$ & $0.99^{*}$ \\
\hline & Cancer & $804(16)$ & $28(23)$ & 0.053 \\
\hline \multicolumn{5}{|c|}{ Falls in past 12 months } \\
\hline & None & $3050(62)$ & $54(44)$ & \multirow[b]{3}{*}{$<0.0001$} \\
\hline & One & $1118(23)$ & $30(24)$ & \\
\hline & 2 or more & $727(15)$ & 40 (32) & \\
\hline
\end{tabular}

*indicates that the p-value comes from Fisher's exact test instead of the chi square test; the cell values were too small for chi square

Table 2. Encounters with the healthcare system (outpatient appointments and inpatient admissions) from the GLOW Baseline Survey

\begin{tabular}{|l|r|c|c|c|}
\hline Outpatient Visits in past 12 months & & Uninjured $(\mathrm{n}=4945)$ & Injured by fall $(\mathrm{n}=124)$ & $\mathrm{p}$ value \\
\hline & None & $249(5.1)$ & $6(4.8)$ & $<0.001$ \\
\hline & 1 to 2 & $1969(40)$ & $31(25)$ & \\
\hline & 3 to 5 & $1664(34)$ & $45(36)$ & \\
\hline Inpatient Admissions in past 12 months & 6 or more & $1021(21)$ & $42(34)$ & \\
\hline & & & & 0.08 \\
\hline & None & $4042(82)$ & $92(74)$ & \\
\hline & 1 & $592(12)$ & $20(16)$ & \\
\hline & 2 & $158(3.2)$ & $6(4.8)$ & \\
\hline
\end{tabular}

Table 3. Cox proportional hazards model predicting fall activation ( $n=4856$ women).

\begin{tabular}{|r|c|c|c|c|c|}
\hline & HR & \multicolumn{2}{|c|}{$95 \% \mathrm{Cl}$} & p-value & Wald chi square \\
\hline Age (per 10 year increase) & 2.365 & 1.983 & 2.821 & $<0.0001$ & 91.7755 \\
\hline Falls at baseline (versus none) & & & & $<0.001$ & 16.3356 \\
\hline Two or more & 1.290 & 0.809 & 2.057 & & \\
\hline Medical history & & & & & \\
\hline High cholesterol & 0.666 & 0.463 & 0.958 & 0.028 & 4.8120 \\
\hline Osteoarthritis & 1.589 & 1.102 & 2.292 & 0.013 & 6.1473 \\
\hline
\end{tabular}

IJOAR: http://escipub.com/international-journal-of-aging-research/ 


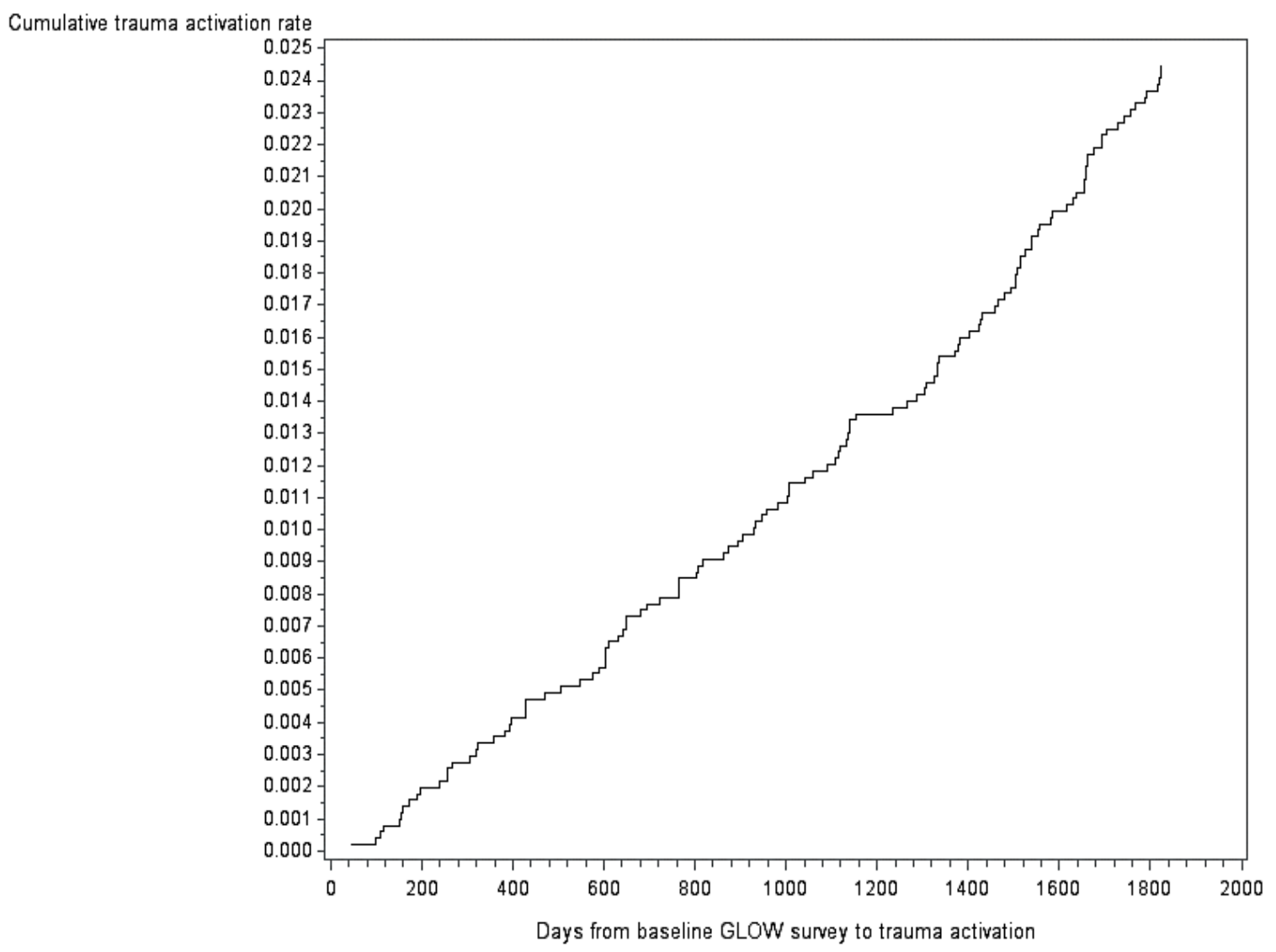

Figure 1a. Kaplan-Meier Curve for Fall-Based Trauma Activation

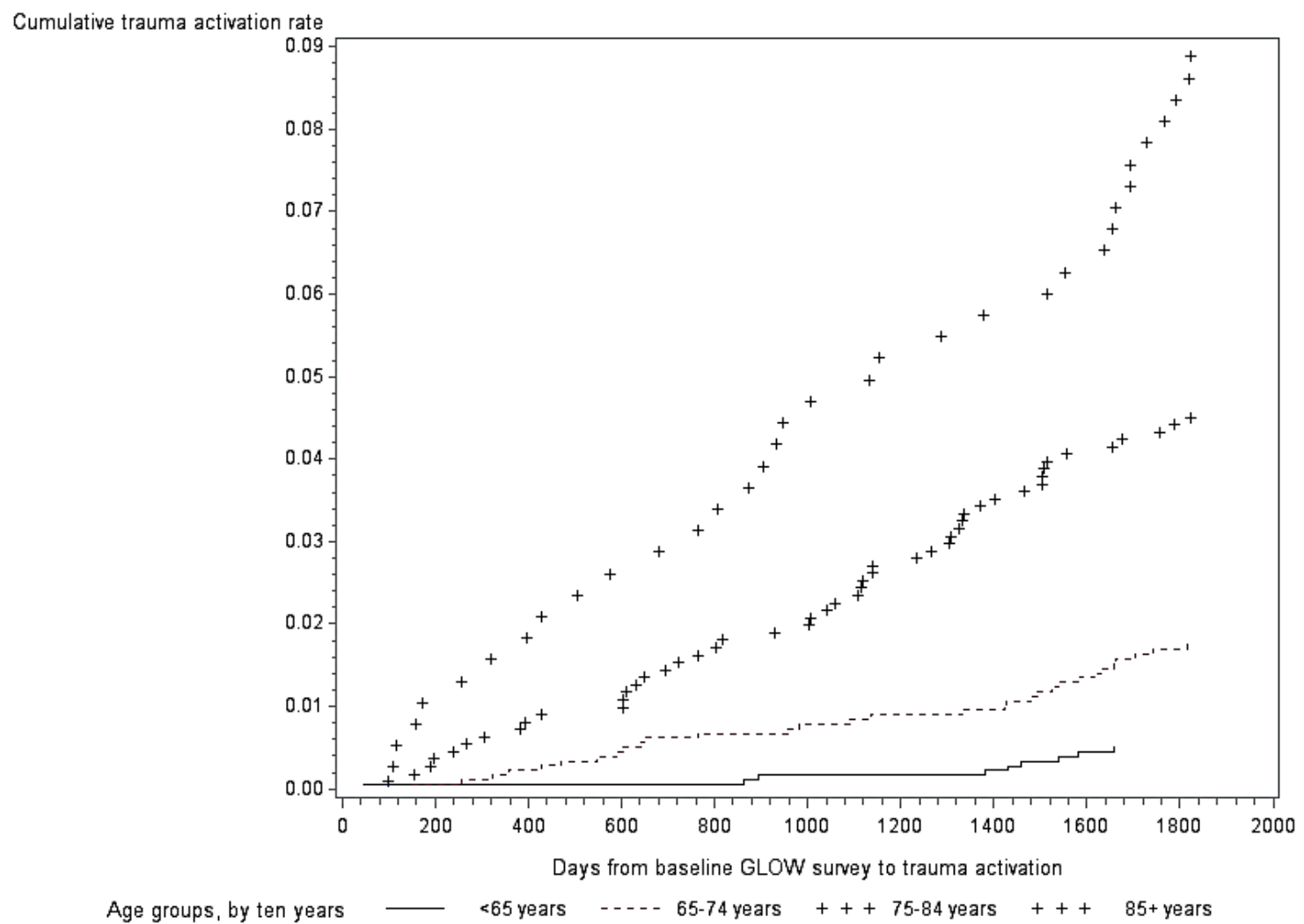

Figure 1b. Kaplan-Meier Curve for Fall-Based Trauma Activation by increasing age (10 year increments) 


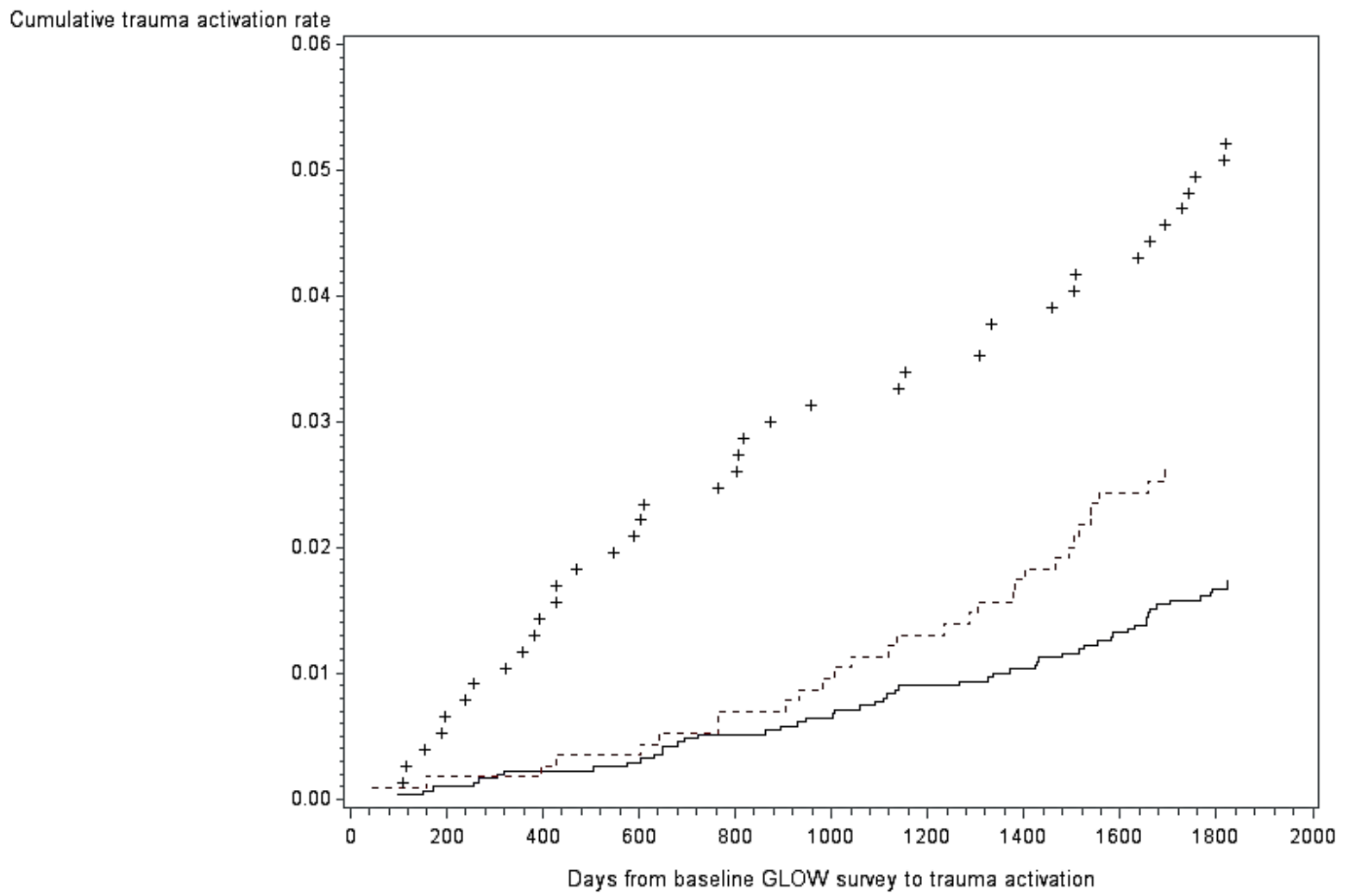

9. How many times fallen $\longrightarrow$ None - - - Once +++2 times or more

Figure 1c. Kaplan-Meier Curve for Fall-Based Trauma Activation by number of self reported falls.

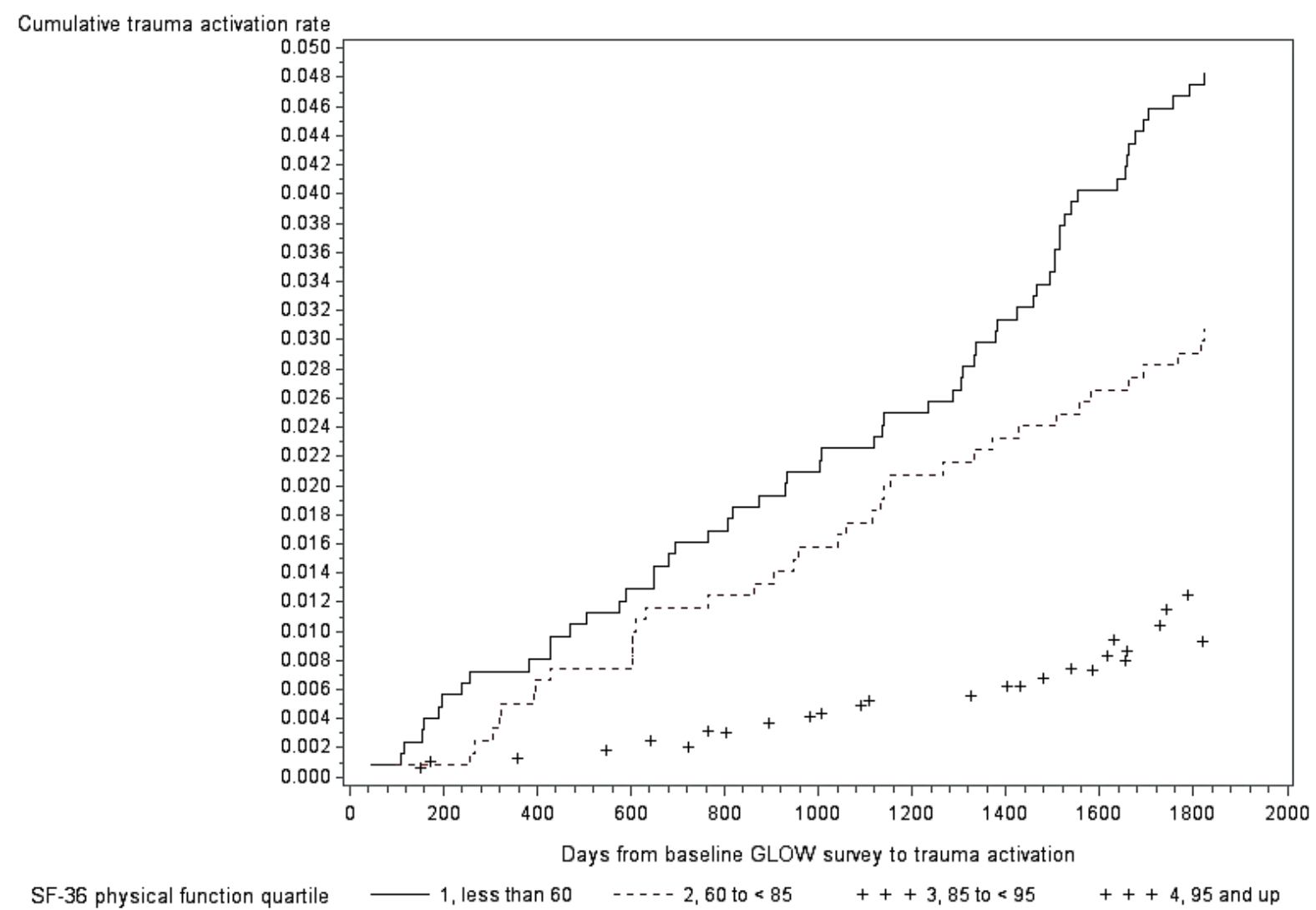

Figure 1d . Kaplan-Meier Curve for Fall-Based Trauma Activation by SF-36 physical function quartile. 


\section{Results}

Of the 5,091 Worcester, MA GLOW cohort, 163 were evaluated for traumatic injury at UMass Memorial during the GLOW study period and after their baseline survey. One hundred and twenty-four women sustained a traumatic injury due to fall (ICD-9-CM Ecode 880-888) during the 1827 days of the GLOW study follow-up. (Figure 1a) This patient population comprised the study group and the 4,945 women who were uninjured comprised the comparison group.

The median age of the injured women was 80 years old (IQ range $72-85$ ) as compared to the uninjured population, 68 years old (IQ 61 -76) ( $p$ value $<0.0001$ ). There were no statistically significant differences in race, with a majority of women (>97\%) identifying as Caucasian. Cardiovascular and pulmonary disease was more prevalent in the injured population (Table 1).

Activity status as assessed by the SF-36 questionnaire is shown in Figure 2. Statistically significant limitations in all activities were selfreported by the injured cohort. Two or more selfreported falls (Table 1) were more common in the injured cohort. Outpatient doctor's visits were also more frequent in the falls group as compared to the comparison population, however inpatient admissions for non-fall related causes were similar (Table 2) between the two groups.
The median injury severity score of the injured cohort was 9 (IQR 9 -10). The most frequent mechanism of fall was from slipping, tripping or stumbling $(n=77,62 \%)$. The next most frequent cause was accidental fall on or from stairs or steps $(n=21,17 \%)$. Two women required mechanical ventilation at arrival and $4(3.2 \%)$ women died from their injuries. Head or extremity injuries were the most common injuries. Femur fractures were the most frequent injury $(n=25, \quad 9.8 \%)$, followed by skin contusion/hematoma to face ( $n=12,4.7 \%)$, skin contusion/hematoma to scalp ( $n=10,3.9 \%)$, and concussion $(n=10,3.9 \%)$. The rate of falls was constant over time for the entire population (Figure 1a). Figures $1 \mathrm{~b}-1 \mathrm{~d}$ show rate of fall from the baseline GLOW survey by age, number of falls (none, once, two or more) and the SF-36 physical function score. The rate of falls was higher with increasing age (10 year increment), increased number of self-reported falls and decreasing SF-36 physical function quartile.

In a Cox proportional hazards model to predict falls the two strongest predictors were age, with a hazard ratio of 2.37 per 10 year increase $(95 \%$ $\mathrm{Cl} 1.98-2.82$, $p$ value $<0.0001$ ), and two or more falls at baseline with a hazard ratio of 2.39 (95\% Cl $1.56-3.65$, p value < 0.001 , Table 3.) Another significant predictor of falls was a medical history of osteoarthritis, HR 1.59 (95\% Cl $1.10-2.29, p=0.03)$.

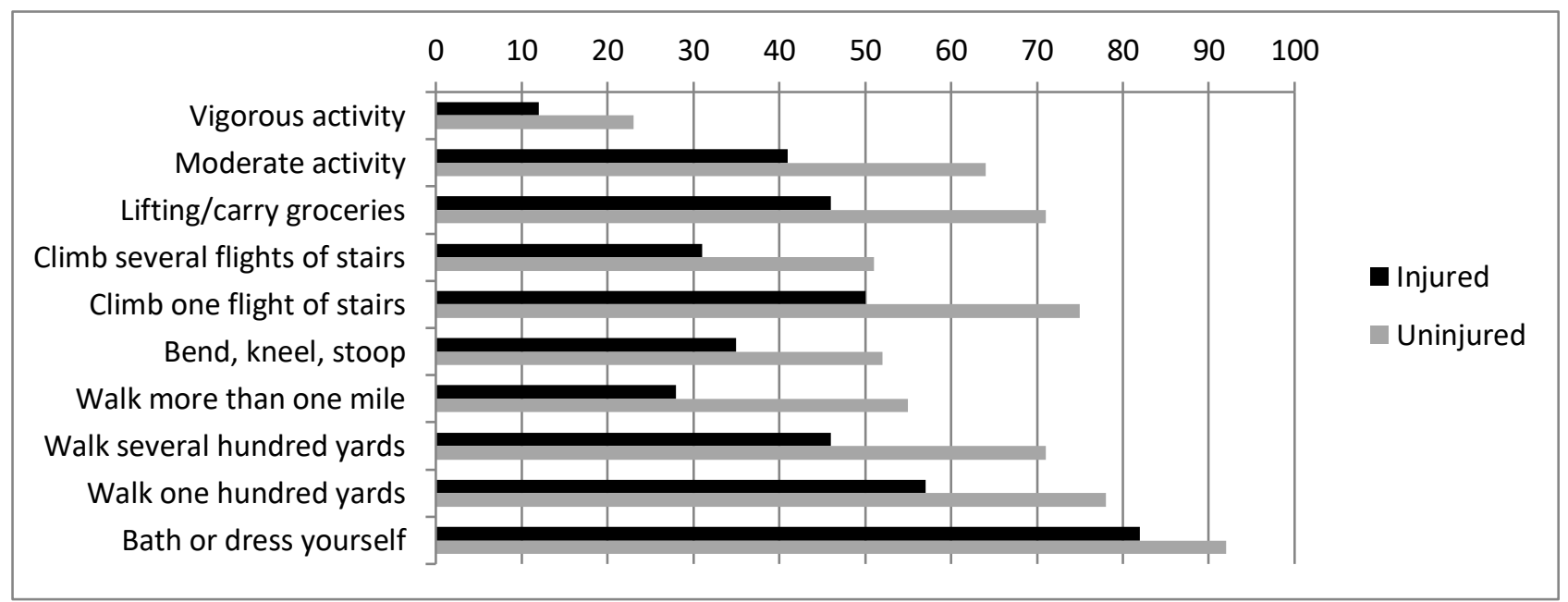

Figure 2. Short Form 36 Activity from the GLOW Baseline Survey (all differences significant $p<0.05$ ) 


\section{Discussion}

Our study was novel in that we had preinjury functional status data on a cohort of elderly women who were evaluated for a fall at a level 1 trauma center. While we had predicted that diminished functional status would be a predictor of falls, we found that age was the strongest predictors of sustaining a fall. Each 10 year increase in age increased the risk of falling increasing nearly two and a half times compared to the youngest age group; meanwhile reported functional status was not significant when accounting for age.

Our findings suggest that best way to conceptualize risk factors of falling in an older population (and therefore appropriate target fall prevention strategies) is frailty. Frailty is defined as physiologic decline in muscle strength, balance and agility that occurs with aging. $(14,15)$. While it is not surprising that functional status would decline with increasing frailty, in our small cohort the absolute value of age was more important than details surrounding day-to-day functional status as is measured in the SF-36. The SF-36 physical function score highest two quartiles had low and similar rates of trauma evaluations. This suggests that the bottom $50 \%$ is the group which have the greatest need for fall prevention intervention.

Prior studies have also found that age is an important predictor. In particular, age over the 80 years old has been one of the most significant risks factors for falling. (16) The Kaplan-Meier curve for the entire injury population was linear, showing that the risk of injurious fall was relatively constant over time with no distinct cut off. The cumulative fall leading to a trauma activation was greater with older age groups when examined by 10 year increments, but again there was no distinct cut off. The KaplanMeier curves appear to be linear, except for the over 85 year old group; as they approach 1800 days from the baseline survey; here the line steepens suggesting an increasing rate of falling.
We also found that both a history of 2 or more prior falls and more frequent outpatient clinical visits were more common amongst those who were treated for fall-related injuries. We did not know the reason for these visits, but it may be related to worsening health status and/or for evaluation after falls not resulting in need for emergency room evaluation. The Kaplan Meier cumulative rate of falling was increased between the groups of no falls, one self-reported fall and two or more self-reported falls, but remained linear during the GLOW study period. Ultimately, both falling more and needing to see your physician more may be markers of increased frailty. While we found that the SF-36 appears to be a cumbersome and not particularly enlightening measure for determining fall risk when age is known, and prior falls can be easily assessed (assuming patients are honest with their physicians), these frequent visits (as many as 6 in one year) do present and opportunity to engage in fall prevention assessment and education over time even when the appearance of frailty may be subtle. Given the near epidemic level of falls in the elderly, national and state organizations have developed programs for balance, strengthening and fall awareness which may be offered the patient at these outpatient visits. (17)

For those who had fallen and sustained injury requiring care at a trauma center, the injury pattern most commonly noted was extremity fractures and head injuries. Given the mechanism, falls and most frequently a fall from standing, this is an expected finding. This pattern correlates with previous studies on geriatric trauma. (4) Falls from standing are a low energy mechanism, however injury severity scores in the elderly are higher than in nongeriatric patients given similar mechanisms. Outcomes are also worse in geriatric patients with higher mortality rates than younger cohorts. $(4,18)$ The mortality rate from trauma extends out for up to a year beyond the index hospital stay. (19) From a hip fracture, the one year mortality may be as high as $36 \%$. (20) Thus, the 
full costs to society from the fall and subsequent injury and complications is much greater than the index hospitalization.

There are limitations to this study. First, the GLOW data while prospective is self-reported. The participants may have embellished their activity status for fear of appearing weak or older. One inherent selection bias comes how the patients were determined to be evaluated by the trauma surgical team. Emergency medical services responds to 911 phone calls. However, individuals may refuse to be transported to the hospital. Then, the decision to activate the trauma team at our institution is made at the discretion of Emergency Medical Services and the Emergency Department physician based on established triage criteria (21). The trauma surgical service will be called to evaluate the most critically ill patients but will not evaluate every patient. While we are the only American College of Surgeons designated trauma center in the area, some patients may not have been transported to UMass, particularly if they had minor injuries. Furthermore, as trauma is not a predictable event, the fall and trauma evaluation occurred a variable time from the GLOW baseline survey. Another limitation is related to the sample size which is restricted as the data was previously collected. The sample size led us to collapse the SF-36 responses into the "no activity limitation" as compared to any respondent limitations. With a larger population, it is possible that differences in specific activities would become more significant than other activity limitations.

Our predictive model for serious injury after falling is simple, requires no additional tests, measurements, questionnaires or calculations. Age and two or more prior falls were determined to be the most significant risk factor for a trauma surgical evaluation for falls. Osteoarthritis was significant as well. This cohort had multiple, in some cases more than 5 , outpatient visits which creates the opportunity to identify this group and enroll them in programs to modify strength and balance to reduce the rate of significant injury from falling. While ageing is inevitable, these patients may be identified for early intervention.

\section{References}

1. Ortman, J. M., Velkoff, V. A., \& Hogan, H. (2014). An aging nation: the older population in the United States (pp. 25-1140). United States Census Bureau, Economics and Statistics Administration, US Department of Commerce.

2. Stevens, J. A. (2010). A CDC compendium of effective fall interventions: What works for communitydwelling older adults.

3. Sterling, D. A., O'connor, J. A., \& Bonadies, J. (2001). Geriatric falls: injury severity is high and disproportionate to mechanism. Journal of Trauma and Acute Care Surgery, 50(1), 116-119.

4. Bergeron, E., Clement, J., Lavoie, A., Ratte, S., Bamvita, J. M., Aumont, F., \& Clas, D. (2006). A simple fall in the elderly: not so simple. Journal of Trauma and Acute Care Surgery, 60(2), 268-273.

5. Barnett, A., Smith, B., Lord, S. R., Williams, M., \& Baumand, A. (2003). Community-based group exercise improves balance and reduces falls in at-risk older people: a randomised controlled trial. Age and ageing, 32(4), 407-414.

6. Li, F., Harmer, P., Fisher, K. J., McAuley, E., Chaumeton, N., Eckstrom, E., \& Wilson, N. L. (2005). Tai Chi and fall reductions in older adults: a randomized controlled trial. The Journals of Gerontology Series A: Biological Sciences and Medical Sciences, 60(2), 187-194.

7. Skelton, D., Dinan, S., Campbell, M., \& Rutherford, O. (2005). Tailored group exercise (Falls Management Exercise-FaME) reduces falls in community-dwelling older frequent fallers (an RCT). Age and Ageing, 34(6), 636-639.

8. Cumming, R. G., Thomas, M., Szonyi, G., Salkeld, G., O'neill, E., Westbury, C., \& Frampton, G. (1999). Home visits by an occupational therapist for assessment and modification of environmental hazards: a randomized trial of falls prevention. Journal of the American geriatrics society, 47(12), 1397-1402.

9. Gillespie, L. D., Robertson, M. C., Gillespie, W. J., Lamb, S. E., Gates, S., Cumming, R. G., \& Rowe, B. H. (2009). Interventions for preventing falls in older people living in the community. Cochrane Database Syst Rev, 2(2).

10. Nikolaus, T., \& Bach, M. (2003). Preventing falls in community-dwelling frail older people using a home intervention team (HIT): results from the randomized Falls-HIT trial. Journal of the American Geriatrics Society, 51(3), 300-305. 
11. Hooven, F. H., Adachi, J. D., Adami, S., Boonen, S., Compston, J., Cooper, C., ... \& LaCroix, A. (2009). The Global Longitudinal Study of Osteoporosis in Women (GLOW): rationale and study design. Osteoporosis international, 20(7), 1107-1116.

12. Rotondo MF, Cribari C, Smith RS ed. (2014) Resources for the optimal care of the injured patient $6^{\text {th }}$ edition. American College of Surgeons.

13. Ware JE, Kosinski M, Dewey JE (2000) How to score version 2 of the SF-36 Health Survey. Quality Metric, Lincoln

14. Lauretani, F., Russo, C. R., Bandinelli, S., Bartali, B., Cavazzini, C., Di lorio, A., ... \& Ferrucci, L. (2003). Age-associated changes in skeletal muscles and their effect on mobility: an operational diagnosis of sarcopenia. Journal of applied physiology, 95(5), 1851-1860.

15. Landi, F., Liperoti, R., Russo, A., Giovannini, S., Tosato, M., Capoluongo, E., ... \& Onder, G. (2012). Sarcopenia as a risk factor for falls in elderly individuals: results from the ilSIRENTE study. Clinical nutrition, 31(5), 652-658.

16.Ambrose, A. F., Paul, G., \& Hausdorff, J. M. (2013). Risk factors for falls among older adults: a review of the literature. Maturitas, 75(1), 51-61.
17.Van Voast Moncada, L. (2011). Management of falls in older persons: a prescription for prevention. American family physician, 84(11).

18. MacKenzie, E. J., Rivara, F. P., Jurkovich, G. J., Nathens, A. B., Frey, K. P., Egleston, B. L., ... \& Scharfstein, D. O. (2006). A national evaluation of the effect of trauma-center care on mortality. New England Journal of Medicine, 354(4), 366-378.

19. Santry HP, Psoinos CM, Wilbert CJ, Flahive JM, Kroll-Desrosiers AR, Emhoff TA, Kiefe Cl. Quadrimodal distribution of death after trauma suggests that critical injury is potentially a terminal disease. (2015) J Critical Care, 30(3):656e1-656e7.

20. Mundi S, Pindiprolus B, Simunovic N, Bhandari M. Similar mortality rate in hip fracture patients over the past 31 years. Acta Orthpaedica (2014), 85(1):54-9.

21. Sasser, S. M., Hunt, R. C., Faul, M., Sugerman, D., Pearson, W. S., Dulski, T., ... \& Cooper, A. (2012). Guidelines for field triage of injured patients: recommendations of the National Expert Panel on Field Triage, 2011. Morbidity and Mortality Weekly Report: Recommendations and Reports, 61(1), 1-20.

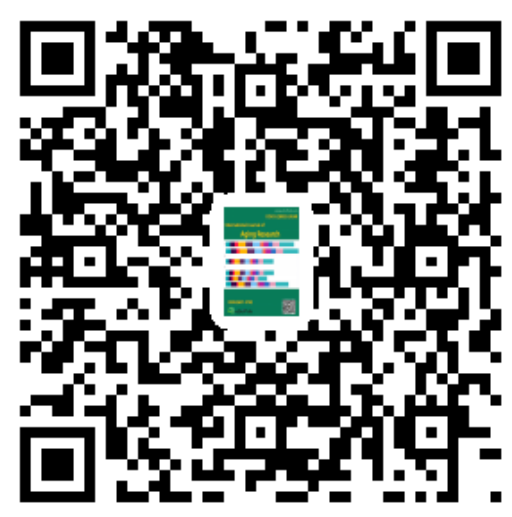

